\title{
Building Public Confidence in Medical Registration Revalidation
}

\author{
Policy Brief: November 2016
}

\section{HOW TO ENSURE THAT DOCTORS REMAIN COMPETENT THROUGHOUT LONG CAREERS IS A CHALLENGE.}

Regular 'revalidation' of medical registration has been proposed as a way to 'affirm or establish the continuing competence of physicians'1-2 whilst strengthening and facilitating ethical and professional 'commitment to reducing errors, adhering to best practice and improving quality of care ${ }^{3}$ by the medical profession.

There is uncertainty about which model of revalidation to implement; should it aim to ensure doctors are just 'up to date' or also 'fit to practise'.

$>$ While patient safety and trust are justifications for revalidation, to date there has been a lack of patient perspectives in the discussion.

$>$ Our research indicates that the general public strongly supports revalidation processes in response to a failure in physician competence.

$>$ Overall the public prefer revalidation models which go beyond being 'up to date', in favour of formal, independent, summative activities designed to ensure doctors are 'fit to practise'.

\section{Background}

\section{The Opportunity}

The Medical Board of Australia ('MBA') is responsible for regulating the medical profession in the public interest. Since 2012, it has been considering the introducing medical registration revalidation. ${ }^{1}$

Revalidation is a practice designed to 'affirm or establish the continuing competence of physicians'2 whilst strengthening and facilitating ethical and professional 'commitment to reducing errors, adhering to best practice and improving quality of care' ${ }^{3}$ by the medical profession.

\section{The Challenge}

There are a many ways that revalidation could be undertaken, ${ }^{1}$ with the MBA currently reviewing options.

A key difference between potential revalidation models is whether revalidation is focused on activities that are either formative (that is, supporting individual learning), summative (ensuring minimum standards of performance) or a mixture of the two. ${ }^{1}$

Neither a formative nor a summative approach is necessarily 'better'. There are advantages and disadvantages attached to each. Instead, the best approach depends upon the particular outcomes we want revalidation to achieve. For example, taking a 'purely' formative approach would lead to doctors being 'up to date', but this would leave out confirmation that they were in fact 'fit to practice' by 
demonstrating minimum standards of performance. So too might a purely summative approach deter some doctors from seeking revalidation, and would require significant resources to administer.

We believe that asking patients or the general public their views is an important contribution to shaping the future of medical registration regulation and health regulation generally. Protection of the public and the public interest are central to the Medical Board of Australia's role in regulating the medical profession. ${ }^{4}$ Patients have been identified as the 'glue'13 at the centre of discussion and justification of revalidation, ${ }^{9}$ and their views and preferences should be given priority with regard to proposed regulatory action which is taken in their name and for their benefit and protection.

\section{The Evidence}

The MBA has recently proposed its preferred approach to revalidation and has sought feedback from both practitioners and the general public. ${ }^{4}$ In aid of helping to ensure that 'patients remain at the heart of medical care', ${ }^{1}$ we utilised a Discrete Choice Experiment (see Appendix) in order to offer some information on patient preferences with regard to revalidation.

We believe that revalidation efforts should be applied in a targeted way. For example, the more summative elements might be applied in response to an identified issue with the 'continuing competence of physicians'2 rather than a broadly applied preventive measure. This aligns with arguments by Archer et al and Bismark et al ${ }^{1,5-8}$ and, more recently, the MBA's Expert Advisory
Group on Revalidation's proposal for proactive identification of doctors who are either 'at risk' or are performing poorly as candidates for summative, or appraisal-like activities. ${ }^{4}$ This has advantages for resource utilisation as well as for increasing the integration of existing healthcare quality and safety systems - such as patient complaints mechanisms - and thereby increasing the patientdirected nature of any proposed system.

To test what the public thought, we had 1000 NSW residents read a short vignette (story) about a failure in physician competence in an ICU.

This was based on a realistic scenario that has been the subject of other research into reducing errors in intensive care units. ${ }^{12}$ We then forced the participants in our experiment to select what they would recommend should happen to both the doctor and nurse in the scenario from two available options. A sample choice set as displayed to respondents is shown in the Appendix.

We report on the choices respondents made in relation to revalidation in this policy brief. There were four revalidation models (or 'levels') used to construct choices shown to respondents. They are presented in Figure 1 below.

\section{The Results}

The integrated formative and summative model of revalidation by formal re-training of the doctor in relevant skills and topic areas was found to be the most attractive revalidation option. This was closely followed by formal review and check of the doctor's skills by an independent senior

\section{ABOUT THE AUTHORS}

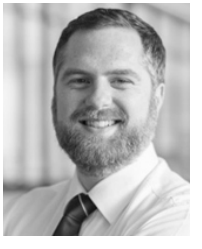

David $\mathbf{J}$ Carter is a lecturer in law at the University of Technology Sydney. His expertise is in research legal and

regulatory challenges in the governance and delivery of safe, effective and sustainable healthcare services.

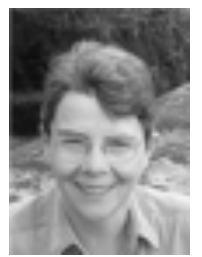

Professor Deborah

Street is a member of the UTS Centre for Health Economics

Research and Evaluation. Her research focuses on

the construction of designed experiments, with particular expertise in the design of optimal Discrete Choice Experiments.

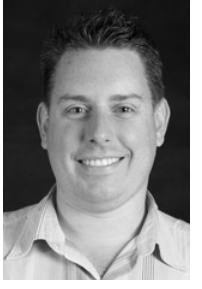

Dr Stephen Bush was formerly a Senior Lecturer School of Mathematical and Physical Sciences. Now working in private industry, Stephen's expertise is in the efficient construction and statistical analysis of experiments.

For further information, please contact David Carter. e: david.carter@uts.edu.au

A full copy of the this Policy Brief is available for download at www.uts.edu.au/staff/david.carter 
doctor; and, finally, a mentoring program and review of the doctor's skills by a colleague from the same hospital.

These results indicate a combination of summative and formative revalidation is likely to be more acceptable to the general public than doing nothing. Moreover, our respondents preferred models which combined summative appraisal ('formal re-training') with formative elements ('re-training', 'in relevant skills and topic areas'), leaning towards those models which included summative activities.

\section{‘...A COMBINATION OF SUMMATIVE AND FORMATIVE REVALIDATION IS PREFERRED, WITH A PREFERENCE FOR INCLUSION OF SUMMATIVE FEATURES.'}

\section{Related Appendices}

$>$ Reference List

$>$ Useful Resources

\section{The Implications}

Our results show that summative forms of revalidation are attractive to the general public. Most popular seems to be a combination of summative and formative elements, with revalidation that involves 'formal' and 'independent' assurance of 'mastery' of skills and knowledge. The implication is that, subject to the DCE's own contextual factors and influences, if presented with revalidation models resembling something like our models of formal re-training of the doctor in relevant skills and topic areas and formal review and check of the doctor's skills by an independent senior doctor, approximately $59 \%$ of choices made by respondents would flow to that revalidation model. A sizeable minority would choose the mentoring option with colleagues from the same hospital and only $15 \%$ would choose to perform no revalidation.

At present, the MBA's Expert Advisory Group of Revalidation proposes an integrated approach to revalidation consisting of two components: a strengthened form of CPD, and proactive identification and assessment of 'at-risk' and poorly performing practitioners. ${ }^{4}$ This represents a mixed-model, integrating largely formative CPD to support individual learning ('up to date') and summative appraisal to ensure minimum standards of performance ('fit to practise'). In practice, the model proposes an arrangement that 'nests' CPD within the second revalidation component, using CPD and other means to assist in identifying 'at risk' or poorly performing medical practitioners by use of compulsory performance review and outcome measurement alongside validated education activities. This means that a form of summative appraisal revalidation activity would be compulsory for all medical practitioners (to satisfy their CPD requirement). This selection of a mixed formative and summative approach is supported by the findings presented here.

Subject to further detail, trial, and successful implementation, it seems likely that the combination of formative and summative assessment proposed by the MBA's Expert Advisory Group on Revalidation will be acceptable o the broader public. Specifically, this mixed-model should be acceptable to the public provided that revalidation is formal, and the summative component is focused on assessing mastery of skills and knowledge through independent, formal means.

\section{Policy Practitioners, Regulators and Decision Makers Should...}

Revalidation should be designed mindful of the views of the public. To achieve this, policy makers, regulators and decision makers should ensure that the at least the following three points are integrated into any revalidation model:

1. Revalidation models should be introduced. Revalidation should be used in response to identified issues of physician competence and logically extended to those identified as being at risk of poor performance. Our choice model shows that when presented with choices between validation models in the context of other existing regulatory responses, approximately $85 \%$ would be for one of the three models of revalidation we presented whilst approximately $15 \%$ of choices made by the public would be for no revalidation process.

2. Revalidation should go beyond formative, informal approaches designed to ensure doctors are 'up to date' only. Our research shows the public are in favour of formal, independent, summative activities designed to ensure doctors are 'fit to practise' particularly in response to a failure in physician competence. Patient's preferences skew towards revalidation efforts which use elements like 'formal review and check' and 'formal retraining' in the doctor's skills and topic areas 'by an independent doctor' rather than by 'colleagues from the same hospital'.

\section{Embed and integrate existing patient-directed quality an safety systems or regulatory mechanisms.}

Revalidation should be part of dynamic mix of health practitioner and quality and safety regulation. Participants in our experiment responded to revalidation efforts in the context existing mechanisms and activities in this space, as such revalidation should work in an integrated fashion with those existing mechanisms including investigative and disciplinary processes, transparency and public reporting, tort and criminal liability. 


\section{Reference List}

1. Archer J, Pitt R, Nunn S, Regan de Bere S. The evidence and options for medical revalidation in the Australian context: Final Report. 2015.

2. Horsley T, Lockyer J, Cogo E, et al. National programmes for validating physician competence and fitness for practice: a scoping review. BMJ Open 2016; 6(4):e010368.

3. Bolsin SN, Cawson E, Colson ME. Revalidation is not to be feared and can be achieved by continuous objective assessment. The Medical Journal of Australia 2015; 203(3): 142-4.

4. The Medical Board of Australia. Options for Revalidation in Australia: Discussion Paper. 2016.

5. Bismark M. Marie Bismark: Gauging Revalidation [Internet]. MJA InSight 2015 [cited 2016 Jul 20]. Available from: https://www.mja.com.au/insight/2015/38/marie-bismark-gauging-revalidation

6. Bismark MM, Brennan TA, Paterson RJ, et al. Relationship between complaints and quality of care in New Zealand: a descriptive analysis of complainants and non-complainants following adverse events. Qual Saf Health Care 2006;15(1):17-22.

7. Bismark MM, Spittal MJ, Gogos AJ, et al. Remedies sought and obtained in healthcare complaints. BMJ Qual Saf 2011; 20(9): 806-10.

8. Bismark MM, Spittal MJ, Gurrin LC, et al. Identification of doctors at risk of recurrent complaints: a national study of healthcare complaints in Australia. BMJ Qual Saf 2013; 22(7): 532-40.

9. Guillemin M, Archer J, Nunn S, de Bere SR. Revalidation: Patients or process? Analysis using visual data. Health Policy 2014; 114(2-3): 128-38.

10.Amaya-Amaya M, Gerard K, Ryan M. Discrete Choice Experiments in a Nutshell. In: Ryan M, Gerard K, Amaya-Amaya M, editors. Using Discrete Choice Experiments to Value Health and Health Care [Internet]. Springer Netherlands; 2008: 13-46. (The Economics of Non-Market Goods and Resources). Available from: http://link.springer.com.ezproxy.lib. uts.edu.au/chapter/10.1007/978-1-4020-5753-3_1 (accessed Sep 2016).

11.Street DJ, Burgess L. The Construction of Optimal Stated Choice Experiments: Theory and Methods. John Wiley \& Sons, 2007.

12.Burrell AR, McLaws M-L, Murgo M, et al. Aseptic insertion of central venous lines to reduce bacteraemia. Med J Aust 2011; 194(11): 583-7.

13.Archer J, Regan de Bere S, Nunn S, Clark J, Corrigan O. "No One Has Yet Properly Articulated What We Are Trying to Achieve": A Discourse Analysis of Interviews With Revalidation Policy Leaders in the United Kingdom. Academic Medicine 2015; 90(1): 88-93.

14.Amaya-Amaya M, Gerard K, Ryan M. Discrete Choice Experiments in a Nutshell. In: Ryan M, Gerard K, Amaya-Amaya M, editors. Using Discrete Choice Experiments to Value Health and Health Care [Internet]. Springer Netherlands; 2008: 13-46. (The Economics of Non-Market Goods and Resources). Available from: http://link.springer.com.ezproxy.lib. uts.edu.au/chapter/10.1007/978-1-4020-5753-3_1 (accessed Sep 2016).

15. Street DJ, Burgess L. The Construction of Optimal Stated Choice Experiments: Theory and Methods. John Wiley \& Sons, 2007.

16.Ryan M, Gerard K, Amaya-Amaya M. Using Discrete Choice Experiments to Value Health and Health Care. Springer Science \& Business Media; 2007.

17.Russo PL, Chen G, Cheng AC, et al. Novel application of a discrete choice experiment to identify preferences for a national healthcare-associated infection surveillance programme: a cross-sectional study. BMJ Open 2016; 6(5): e011397.

18. de Bekker-Grob EW, Ryan M, Gerard K. Discrete choice experiments in health economics: a review of the literature. Health Econ 2012; 21(2): 145-72.

19. de Bekker-Grob EW, Donkers B, Jonker MF, Stolk EA. Sample size requirements for discrete-choice experiments in healthcare: a practical guide. Patient 2015; 8(5): 373-384.

20.Johnson FR, Lancsar E, Marshall D, et al. Constructing experimental designs for discrete-choice experiments: report of the ISPOR conjoint analysis experimental design good research practices task force. Value in Health 2013; 16(1): 3-13.

\section{PATIENT VIEWS AND}

PREFERENCES SHOULD BE GIVEN PRIORITY WITH REGARD TO PROPOSED REGULATORY ACTION WHICH 


\section{APPENDICES}

\section{SAMPLE CHOICE SET}

\begin{tabular}{|c|c|c|}
\hline & Option A & Option B \\
\hline $\begin{array}{l}1 \text { Government-issued fine for } \\
\text { the doctor }\end{array}$ & No fine for the doctor & $\begin{array}{l}\text { A fine equivalent to one month } \\
\text { of the doctor's salary }\end{array}$ \\
\hline $\begin{array}{l}2 \text { Restriction on future medical } \\
\text { practice for the doctor by the } \\
\text { Medical Registration Board }\end{array}$ & $\begin{array}{l}\text { Noting the incidence on the } \\
\text { doctor's permanent medical } \\
\text { registration record }\end{array}$ & $\begin{array}{l}\text { Permanent cancellation of their } \\
\text { registration as a medical } \\
\text { practitioner }\end{array}$ \\
\hline $\begin{array}{l}3 \text { Criminal trial for } \\
\text { manslaughter for the doctor }\end{array}$ & $\begin{array}{l}\text { Criminal trial of the doctor for } \\
\text { manslaughter with a finding of } \\
\text { Guilty but with no imprisonment }\end{array}$ & $\begin{array}{l}\text { Criminal trial of the doctor for } \\
\text { manslaughter with a finding of } \\
\text { Guilty but with no imprisonment }\end{array}$ \\
\hline $\begin{array}{l}4 \text { Restriction on future nursing } \\
\text { practice for the nurse by the } \\
\text { Nursing and Midwifery Board }\end{array}$ & $\begin{array}{l}\text { Temporary suspension of the } \\
\text { nurse's registration and right to } \\
\text { work as a nurse }\end{array}$ & $\begin{array}{l}\text { No restriction on practice or } \\
\text { disciplinary proceedings against } \\
\text { the nurse }\end{array}$ \\
\hline $\begin{array}{l}5 \text { Publicity and public reporting } \\
\text { of the incident }\end{array}$ & $\begin{array}{l}\text { No publicity or reporting of the } \\
\text { incident. }\end{array}$ & $\begin{array}{l}\text { A public Facebook status } \\
\text { appears condemning the doctor } \\
\text { for their actions. }\end{array}$ \\
\hline $\begin{array}{l}6 \text { Verification of the doctor's } \\
\text { skills }\end{array}$ & $\begin{array}{l}\text { A mentoring program and review of } \\
\text { the doctor's skills by a colleague } \\
\text { from the same hospital. }\end{array}$ & $\begin{array}{l}\text { Formal review and check of the } \\
\text { doctor's skills by an } \\
\text { independent senior doctor }\end{array}$ \\
\hline $\begin{array}{l}\text { Choose which option you } \\
\text { prefer: }\end{array}$ & Option A $\square$ & Option B $\square$ \\
\hline
\end{tabular}

Sample Choice Set: This table reproduces a sample choice set as presented to respondents. A DCE constructs these possible recommendations by varying the 'levels' of different 'attributes'. These hypothetical recommendations were constructed by changing the levels (rightmost two columns) of six attributes (listed in the leftmost column).

\section{REVALIDATION MODELS}

Options Used to Generate Choice

Experiment: Which alternative

would you choose...for verification

of the doctor's skills?

No verification processes for the doctor.

A mentoring program and review of the doctor's skills by a colleague from the same hospital.

Formal re-training by the doctor in relevant skills and topic areas.

Formal review and check of the doctor's skills by independent senior doctor.
Matching Revalidation Models Considered by the Medical Board of Australia's Expert Advisory Group (Archer et al) ${ }^{1}$

No Revalidation

up to date'

(Formative)

up to date' + 'fit to practise'

(Formative \& Summative)

fit to practise'

(Summative)
Revalidation Models:

This table sets out the revalidation models which were shown to participants in our experiment. They were constructed to act as proxies for revalidation models proposed by Archer et al, ${ }^{1}$ presented in work commissioned by the Medical Board of Australia. 


\section{Methods}

옴
울
뜰

Discrete choice experiments (DCEs) present respondents with a short scenario or vignette, after which they are shown, sequentially, a number of pairs of potential responses and forced to choose their preferred response from each pair. ${ }^{10-11}$ The underlying premise is that respondents choose what they value in the context in which they are asked to make the choice. ${ }^{14}$

DCE methods have been applied successfully in a variety of health and health system-related contexts. ${ }^{15-18}$ For instance, de Bekker-Grob et al identified 69 published choice-based studies in health care in 2012,19 whilst the ISPOR task force gives a checklist for such studies. ${ }^{20}$

In our study we described an adverse event scenario to respondents and then presented them with several pairs of possible recommendations about what should happen to the health professionals involved in the adverse event. On each occasion respondents had to choose the recommendation they felt more appropriate. In total, respondents were shown 16 pairs of recommendations.

A DCE constructs these possible recommendations by varying the 'levels' of different 'attributes'. These hypothetical recommendations were constructed by changing the levels of six attributes. In our design this results in $4^{6}=4096$ possible recommendations and therefore a total of $4096 \times 4095 / 2=8,386,560$ possible pairs of recommendations. Attributes and their attendant levels were constructed by literature review and regulatory knowledge, with the four levels attempting to convey, in significantly truncated form, the current regulatory setting of 'no revalidation' (Level 0) alongside revalidation approaches, particularly those models proposed by Archer et al in commissioned research for the Medical Board of Australia. ${ }^{1}$
Methods:

This section describes the Discrete Choice Method applied in our research. 